\title{
BMJ Open At cancer diagnosis: a 'window of opportunity' for behavioural change towards physical activity. A randomised feasibility study in patients with colon and breast cancer
}

\author{
Tom Møller, ${ }^{1}$ Christian Lillelund, ${ }^{1}$ Christina Andersen, ${ }^{1}$ Bent Ejlertsen, ${ }^{2}$ \\ Lone Nørgaard, ${ }^{2}$ Karl Bang Christensen, ${ }^{3}$ Eva Vadstrup, ${ }^{2}$ Finn Diderichsen, ${ }^{3}$ \\ Carsten Hendriksen, ${ }^{3}$ Kira Bloomquist, ${ }^{1}$ Lis Adamsen ${ }^{1,3}$
}

To cite: Møller T, Lillelund C, Andersen $\mathrm{C}$, et al. At cancer diagnosis: a 'window of opportunity' for behavioural change towards physical activity. A randomised feasibility study in patients with colon and breast cancer. BMJ Open 2013;3:e003556. doi:10.1136/bmjopen-2013003556

- Prepublication history for this paper is available online. To view these files please visit the journal online (http://dx.doi.org/10.1136/ bmjopen-2013-003556)

Received 5 July 2013 Revised 3 September 2013 Accepted 24 September 2013

CrossMark

For numbered affiliations see end of article.

Correspondence to

Tom Møller;

tom@ucsf.dk la@ucsf.dk

\section{ABSTRACT}

Introduction: Challenges exist in identifying, recruiting and motivating sedentary patients with cancer to initiate physical activity towards recommended levels. We hypothesise that the onset period of adjuvant chemotherapy can be 'the open window of opportunity' to identify and motivate sedentary patients with breast and colon cancers, at risk for developing coronary heart disease, to initiate and sustain lifestyle changes.

Aims: To investigate the feasibility of oncologists/ nurses screening for physical inactivity, in order to identify and recruit an at-risk population of sedentary patients with breast or colon cancer at the onset of adjuvant chemotherapy. Furthermore, the study will examine the adherence to one of two multimodal exercise interventions lasting 12 weeks; (1) hospitalbased, high intensity, group exercise intervention (2) home-based, low intensity, individual, pedometer intervention. Both arms will be compared with a control group.

Methods and analyses: All newly referred patients will be screened for sedentary behaviour, using national recommendations. Testing at baseline, 6 , 12 and 39 weeks will include; (1) physiological testing $\left(\mathrm{VO}_{2}\right.$-peak, one repetition maximum muscle strength and lung function (2) fasting full body dual-energy X-ray absorptiometry scan (3) fasting blood glucose, insulin, lipids and cholesterols, (4) psychometric questionnaires (general well-being, quality of life, anxiety and depression, motivational readiness). The randomised controlled trial feasibility design is selected in order to examine barriers for recruitment, programme adherence, safety aspects and potential efficacy to the interventions during adjuvant chemotherapy.

Ethics and dissemination: The Scientific Committee of the Capital Region (case No. H-1-2011-131) and the Danish Data Protection Agency (j. No. 2011-41-6349) approved the study. Data will be entered and locked into a database hosted by the Copenhagen Trial Unit, Rigshosptialet. Data will be available for analyses to

\section{ARTICLE SUMMARY}

Strengths and limitations of this study

- Limited data exist regarding adherence to and the clinical effects of, multimodal exercise interventions in preillness sedentary patients with cancer undergoing chemotherapy.

- Cardiorespiratory fitness represented as $\mathrm{VO}_{2}$-peak is the primary outcome. To ensure valid and reliable data, cycle ergometer testing and direct continuous measurements of respiratory gas exchange will be utilised at baseline and after the 12-week intervention.

- The qualitative evaluation of the patients' motivation for and participation in, the exercise interventions will serve as a basis for validating and monitoring the two interventions.

- The size of the population in this feasibility study is limited and therefore no conclusion can be drawn regarding the efficacy of the interventions. Furthermore, the present study is not powered to draw conclusions of causality.

- A randomised controlled trial is planned upon completion of the feasibility study.

project members and the trial statistician after the 45 included patients have completed the 12-week test. Results will be published in peer-reviewed scientific journals.

Trial registration: Current Controlled Trials ISRCTN24901641.

\section{BACKGROUND}

Breast and colon cancers are two of the most common cancers, with 4637 patients with breast cancer and 2551 with colon cancer diagnosed annually in Denmark in 2011. Improved cancer treatment has increased 
the number of survivors with an expected 5-year survival rate of $79 \%$ for patients with breast cancer and $52 \%$ for patients with colon cancer. ${ }^{12}$

Several clinical studies exploring the effectiveness of antineoplastic drugs and related toxicity have found that treatment-related symptoms and side-effects (pain, arthralgia, neuropathia, ${ }^{3-6}$ fatigue,${ }^{7-10}$ nausea and vomiting $^{11}{ }^{12}$ weight gain ${ }^{13}{ }^{14}$ myelosuppression and febrile neutropenia, ${ }^{15}{ }^{16}$ skin rash and skin toxicities ${ }^{17}{ }^{18}$ ) may occur at moderate-to-severe intensity, and with significant prevalence among patients undergoing adjuvant chemotherapy. Furthermore, antineoplastic treatment is synonymous with an inactive daily life for a substantial number of patients ${ }^{19}$ and it has been shown that psychological symptoms of anxiety and depression are significantly elevated. ${ }^{20-22}$

During the last decades, exercise oncology has emerged with significant growth due to its potential to alleviate symptom burdens, improving health throughout the cancer continuum and for supporting cancer survivorship. ${ }^{23-27}$ A recent Cochrane review found that the potential benefits of exercise are not homogenous across cancer populations, although exercise interventions of moderate-to-vigorous intensity appear to favour positive outcomes (physical functioning, role functioning, social functioning, fatigue) compared with low-intensity exercise programmes. ${ }^{28}$ In addition, observational studies have consistently suggested that regular physical activity among patients with breast or colon cancer may reduce the incidence and risk of relapse. ${ }^{29-32}$ Other studies have found an elevated-to-high prevalence of predisposing lifestyle factors (weight gain, hypertension, metabolic dysfunction, physical inactivity, smoking) and an increased risk of developing heart disease among patients with cancer. $^{33} 34$ These important clinical and lifestyleassociated factors necessitate the integration of lifestyle modifications in the oncology rehabilitation field ${ }^{35-38}$ and the promotion of increased physical activity for sedentary cancer survivors. So far, only few studies incorporates patients with colon cancer during adjuvant chemotherapy. ${ }^{39}$

Denmark-Wahnefried $e t a l \mathrm{~s}^{40}$ review, 'Riding the Crest of the Teachable moment' suggests that cancer survivors spontaneously adopt lifestyle changes (ie, smoking cessation, diet and physical activity) in the hope of attaining improved health. This gave rise to defining the period of diagnosis as 'the teachable moment ${ }^{40} 41$ and has been documented in clinical studies. ${ }^{42}$ Results from own research confirm that newly diagnosed patients seek selfmanagement strategies when facing their cancer diagnosis. ${ }^{43-47}$ However, it remains unclear what the optimal setting, dosage and combination of exercise and health promoting components that may best facilitate patient adherence, symptom management, sustainable lifestyle changes and long-term health effects in this at-risk population of physically inactive patients with cancer.

The purpose of the present study was to investigate the feasibility of oncologists/nurses screening for physical inactivity, in order to identify and recruit an at-risk population of sedentary patients with breast or colon cancer. The target group will comprise of patients with breast or colon cancer receiving adjuvant chemotherapy that, at 3 months prediagnosis, did not adhere to national recommendations for physical activity based on self-report (150 min of regular and moderate recreational physical activity and at least $2 \times 20 \mathrm{~min}$ of strenuous exercise per week). ${ }^{48}$ Furthermore, the study will examine the adherence to one of two multimodal exercise interventions lasting 12 weeks with the first being a hospital-based, high intensity, group exercise intervention and the second being a home-based, low intensity, individual, pedometer intervention. The goal of the exercise intervention is to (1) increase physical capacity ( $\mathrm{VO}_{2}$-peak), physical activity, functional level and wellbeing, (2) reduce symptom and side-effect burden and (3) encourage sustained lifestyle changes. Both arms will be compared with a randomly selected control group.

\section{DESIGN AND METHODS}

\section{Participants and setting}

Forty-five screened patients with colon or breast cancer referred to adjuvant chemotherapy, with performance status $0-1$, and verified as physically inactive, will be recruited from the oncology department at the Copenhagen University Hospital (Rigshospitalet). Patients with breast cancer with positive or negative oestrogen receptors and regardless of their human epidermal growth factor receptor 2 status will be recruited for the study. Likewise, patients radically operated for stages II and III colon or upper rectum cancer, with or without ostomy construction, will be recruited. All patients will undergo standard or protocol adjuvant chemotherapy, for example, three series of epirubicin and cyclophosphamide followed by three series of docetaxel as standard treatment for breast cancer or six series of docetaxel plus cyclophosphamide if receiving the READ protocol. ${ }^{49}$ Patients with colon cancer typically undergo 12 series of FOLFOX (oxaliplatin and 5-FU (5-flourouracil) and folinic acid) or six series if entering the SCOT protocol. ${ }^{50}$ Patients with colon cancer receiving adjuvant capecitabine may also be eligible candidates. The administered chemotherapy doses will be registered prospectively using predesigned forms and the use of all supportive care will be recorded including growth factors, antiemetics and analgesics.

\section{Procedures}

All newly referred patients with cancer will be screened for sedentary behaviour using national recommendations $^{48}$ by treating nurses/physicians (figure 1) and encouraged to initiate or continue physical activity during treatment. Patients reporting physical activity levels below the recommended level will be referred to the research team and matched against the exclusion criteria. These criteria are in accordance with 


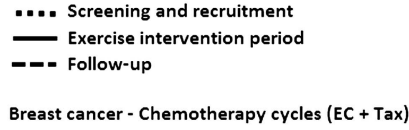

Colon cancer - Chemotherapy cycles (FOLFOX)

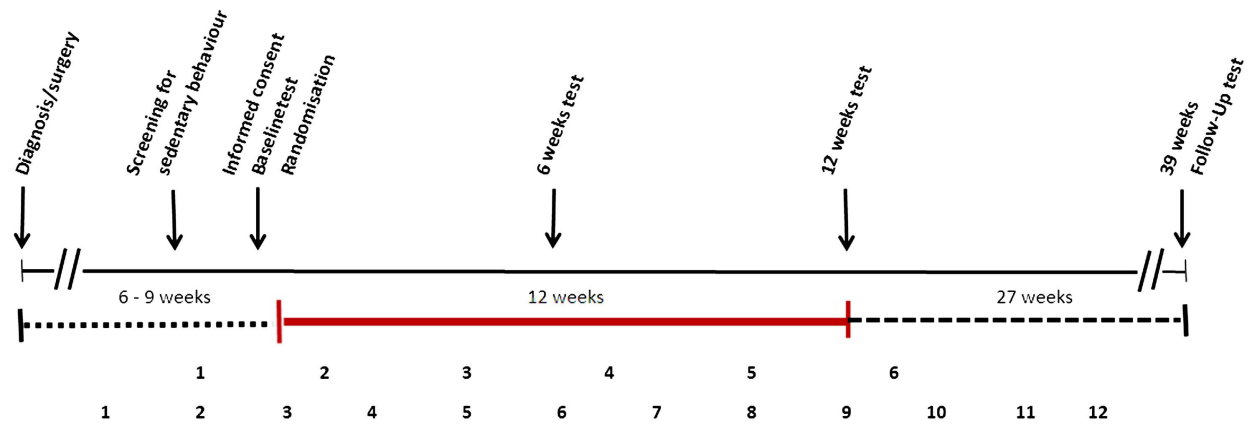

Figure 1 Global overview of study evaluation during chemotherapy.

well-established screening criteria for symptomatic competitive cardiac diseases and comorbidity developed during the 'Body \& Cancer' programme in Denmark. ${ }^{51}$ Furthermore, these criteria are based on general guidelines for cardiorespiratory exercise testing in clinical oncology research ${ }^{52}$ (ie, symptomatic cardiac disease, persistently elevated blood pressure with diastolic pressure $>100$, angina, receiving nitroglycerine, irregular heartbeat and pathological resting pulse $>110$, acute coronary heart syndrome within the last 6 months or pathological ECG changes). Patients with a history of cardiac disease will be discussed with their primary attending oncologist before entering the study.

Written and oral information regarding study rationale, ethics, randomisation and group allocation will be delivered by the primary investigator. Following receipt of informed written consent prior to the baseline visit, patients will be scheduled for a $3.5 \mathrm{~h}$ baseline test session comprised of (1) fasting full body dual-energy x-ray absorptiometry (DXA) scan; (2) fasting blood glucose, insulin, lipids and cholesterols; (3) physiological testing ( $\mathrm{VO}_{2}$-peak, muscle strength and lung capacity) and (4) patient-reported outcome (PRO) questionnaires. Baseline tests will be performed at the Department for Nuclear and Physiologic Medicine and at our training facility located at the Copenhagen University Hospital (Rigshospitalet). A clinical nurse specialist will examine current health, immune and infection statuses prior to the physiological assessments. Upon infection, ongoing antibiotic treatment or presence of 'drug' (chemotherapy)-related vasovagal complaints or irregular pulse or blood pressure, the physiological assessment will be delayed pending complete recovery. Following the baseline test, a brief feedback of the test results will be provided before randomisation and group allocation.

\section{Group allocation/randomisation}

Following baseline testing, patients will be sequentially numbered, stratified by diagnosis and randomised (equal weight $1: 1: 1$ ) by a computer programme located in the Copenhagen Trial Unit (CTU). Patients will be allocated to one of the three study groups: (1) a hospital-based, supervised group exercise intervention of moderate-to-high intensity three times weekly, health promotion counselling and symptom management coaching or (2) a home-based individual pedometer programme, health promotion counselling and symptom management or (3) a control group (table 1).

The study will enrol 45 patients, for example, 30 patients with breast cancer and 15 patients with colon cancer. The feasibility study will serve as a platform for programme feasibility and will be adjusted prior to a planned randomised controlled trial (RCT). The reason for including a control group in the feasibility study is based on earlier experience with own interventional exercise research, where it has been found that patients allocated to a control group, to a considerable extent, refuse to participate in a research exercise programme unless they are offered to participate in the intervention following the study period.

\section{Blinding, masking and data protection}

Personnel conducting follow-up testing will be blinded to study arm assignment. An oncology nurse specialist will enter physiological variables, PRO questionnaires and clinical data (disease and treatment data from medical records) into a database hosted by the CTU, who exclusively has access to unblinded data. The research team and testing personnel will have limited access to data, with approved access from the CTU only provided to the trial statistician $(\mathrm{KBC})$ and the primary investigator (TM) on completion of the intervention. Printouts of baseline characteristics may be approved by the CTU in order to identify and describe patients selected to participate in the semistructured qualitative interviews. Qualitative investigations at 12 weeks will be performed by a researcher not involved in the intervention (LA) and at follow-up (KB; 39 weeks from baseline testing).

\section{Exercise training protocols (general considerations)}

A large observational study that prospectively examined physical activity levels in relation to mortality among 252925 women and men aged 50-71 years, demonstrated that individuals who undertook $30 \mathrm{~min}$ of daily, 
Table 1 Hospital-based supervised group exercise intervention

\begin{tabular}{|c|c|c|c|c|}
\hline \multicolumn{5}{|l|}{ Weekly schedule } \\
\hline Monday & Tuesday & \multicolumn{2}{|l|}{ Wednesday } & Friday \\
\hline \multicolumn{5}{|l|}{ Part I: 6 weeks $9 \mathrm{~h} /$ week } \\
\hline Physical exercise (1.5 h) & $\begin{array}{l}\text { Body } \\
\text { awareness } \\
(1.5 \mathrm{~h})\end{array}$ & \multicolumn{2}{|c|}{ Physical exercise (2 h) } & Physical exercise (1.5 h) \\
\hline Relaxation $(0.5 \mathrm{~h})$ & $\begin{array}{l}\text { Relaxation } \\
(0.5 \mathrm{~h})\end{array}$ & \multirow{2}{*}{\multicolumn{2}{|c|}{ Relaxation (0.5 h) }} & Relaxation (0.5 h) \\
\hline Massage $(0.5 \mathrm{~h})$ & & & & Massage $(0.5 \mathrm{~h})$ \\
\hline \multicolumn{4}{|c|}{$\begin{array}{l}\text { Part II: } 6 \text { weeks all-sport training } 6 \mathrm{~h} / \text { week } \\
\text { Physical exercise }(2 \mathrm{~h}) \\
\text { eg, ballgames, dancing, } \\
\text { resistance and cardio training }\end{array}$} & $\begin{array}{l}\text { Physical exercise }(2 \mathrm{~h}) \\
\text { eg, ballgames, dancing, } \\
\text { resistance and cardio training }\end{array}$ \\
\hline Baseline & Week 6 & & Week 12 & Week 39 \\
\hline $\begin{array}{l}\text { Health counselling and } \\
\text { symptom management }(1 \mathrm{~h})\end{array}$ & $\begin{array}{l}\text { Health cou } \\
\text { symptom } \mathrm{m}\end{array}$ & $\begin{array}{l}\text { ng and } \\
\text { yement }(1 \mathrm{~h})\end{array}$ & $\begin{array}{l}\text { Health counselling and } \\
\text { symptom management }(1 \mathrm{~h})\end{array}$ & $\begin{array}{l}\text { Health counselling and } \\
\text { symptom management ( } 1 \mathrm{~h})\end{array}$ \\
\hline
\end{tabular}

moderate physical activity reduced their mortality rate by $30 \%$ compared with physically inactive individuals. ${ }^{53}$ Furthermore, the study found that individuals who had engaged in high-intensity exercise of $3 \times 20 \mathrm{~min}$ weekly, reduced their mortality rate by $50 \%$ compared with inactive persons. ${ }^{53}$ As such, there appears to be a health gain potential related to both moderate and highintensity physical activity. Physiological markers ( $\mathrm{VO}_{2}$-peak, heart rate, etc) are useful measures of moderate and high-intensity training with the largest gains seen at highest intensity levels (85-95\%). Low-intensity training $(60-85 \%)$ can similarly result in fitness gains; however, gains are less pronounced. ${ }^{54-57}$

\section{Study arm 1}

Supervised hospital-based group exercise intervention+health promotion counselling and symptom management (6 weeks; $9 \mathrm{~h} /$ week+6 weeks; $6 \mathrm{~h} /$ week) $n=15$ : patients will be offered a 12-week exercise programme at our training and testing facilities located adjacent to the Copenhagen University Hospital. Training sessions, in groups of 1014 patients, will be supervised by an exercise physiologist/physiotherapist (CL) and a clinical nurse specialist with experience in oncology and exercise (CA). The training protocol is founded on a well-tested 6-week exercise programme entitled 'Body \& Cancer' ${ }^{51}$ that has been offered to patients with various cancer diagnoses since 2007. The first 6 weeks (Part 1; $9 \mathrm{~h} /$ week) will include three training sessions per week comprising of high-intensity/low-intensity components: warm-up, resistance training, cardiorespiratory training, relaxation and massage, as well as one restorative session per week (for details see previous publications ${ }^{51} 58$ ). The total training volume will correspond to 43 MET hours per week. ${ }^{51}$ An 'all-sports' training element including ball games, dance and circuit training will be introduced during the last
6 weeks of the intervention (Part 2; $6 \mathrm{~h} /$ week) with a total training volume of 40 MET hours per week. Furthermore, patients will receive individual health promotion counselling and symptom management (Part 3) at baseline, 6, 12 and 39 weeks. Pre-exercise screening: This will take place before each session that involves moderate-to-high-intensity physical training. ${ }^{5158}$

\section{Part I: Cardiorespiratory training}

Training will predominantly be performed on stationary bikes (Monarch). Cardiorespiratory training, with the exclusion of a short warm-up, will involve interval training on stationary bicycles with a workload of 70-250 W, equivalent to $85-95 \%$ of each patient's HRmax and with a progressive duration of $60-90 \mathrm{~min} /$ week for 6 weeks. In cases of malaise or risk of overload, the resistance load will be lowered. All patients will wear a heart rate monitor during training sessions, and heart rate will be continuously monitored during all training sessions in order to measure training intensity.

\section{Resistance training}

The aim is to accomplish three continuous sets of 5-8 repetition maximum (RM) ${ }^{59}$ Loads will be based on the patients' individual maximum muscle strength measured with the $1 \mathrm{RM}$ test and adjusted every third week applying the results of a new $1 \mathrm{RM}$ test. ${ }^{59}$ Resistance training will be performed on Technogym equipment (Gambettola, Italy) and will involve chest press; leg press; knee extension; latissimus pull down, lower back extension and abdominal flexion.

\section{Low-intensity training}

The low-intensity training will comprise of three components: relaxation, body awareness training and massage. Relaxation training will be based on principles of 
progressive muscle relaxation. ${ }^{60}$ Body awareness training will adopt various themes that focus on the participant's awareness, recognition and body control. ${ }^{61}$ Massage will be relaxing, facilitative or therapeutic and will include scar tissue massage. ${ }^{62}$

\section{PART II}

Part II will expand on part I in terms of cardiorespiratory and resistance training, with the low-intensity components being discontinued. Part II is based on research studies of healthy untrained men and women finding that exercise-based team sports are as effective as running, in promoting physical capacity and cardiorespiratory health. ${ }^{63-65}$ Improvements in aerobic capacity appear to be independent of exercise type, but rather are dependent on duration, frequency and intensity. ${ }^{66}$ The all-sports training component will encompass three different themes that each will constitute six training sessions. Based on MET calculations ${ }^{67}$ the activities will be equivalent to 21-27 MET hours per week. The first theme will focus on various ball games, including competitive elements, and will provide an estimated intensity of 7-9 MET hours. Theme two will focus on dancing activities (eg, zumba) and will render an estimated intensity of 7-9 MET hours. Theme three will comprise of different circuit training games, rendering an estimated intensity of 7-9 MET hours.

\section{Study arm 2}

Home-based individual progressive pedometer intervention, health promotion counselling and symptom management: $\mathrm{n}=15$ (table 2).

Individual pedometer instruction will be provided by a clinical nurse specialist at our facility. With the pedometer we hope to facilitate, motivate and enhance physical activity levels during chemotherapy. Furthermore, the goal of pedometer use is to promote sustainable long-term behavioural change post-treatment, by integrating exercise in activities of daily living. The overall goal is to avoid physical inactivity and to achieve 10 steps/day, five times per week, equivalent to a low/moderate recreational physical activity level of $30 \mathrm{~min} /$ day. ${ }^{68}$ The patients will: (1) be issued a pedometer as well as scheduled instruction and evaluation; (2) receive individual face-to-face and telephone health promotion counselling, including clinical advice concerning symptom management from a clinical nurse specialists (TM and CA) within oncology-exercise (at baseline, and at weeks 6, 12 and 39). Patients will be allowed to increase their physical activity and may attend municipality-led rehabilitation programmes when recommended as part of their standard care.

\section{Pedometer intervention}

Patients will be requested to maintain their normal physical activity levels during the first week as these will serve as baseline measurements for weekly evaluations. A plan for increased physical activity will be made during face-to-face evaluations at weeks 2, 4, 6 and 12. Patients will be encouraged to increase their physical activity levels stepwise, by at least $25 \%$ compared with their baseline levels. Pedometer steps are entered into a computer-based programme that can visualise the patient's exercise achievements on a daily, weekly and monthly basis.

\section{Health promotion counselling and symptom management} Health promotion counselling will be provided to the patients in study arms 1 and 2. The counselling component is inspired by Albert Bandura's Social Cognition Theory and construct of self-efficacy that considers every individual as proactive, reflective and self-regulating. Further, this theory holds that expectations of own abilities, and experience of competence to act and to set goals are essential to human behaviour and behavioural change. ${ }^{69} 70$ The theoretical basis of Bandura's theory is detailed in Marcus et $a l \mathrm{~s}^{71}{ }^{72}$ construction of 'Exercise Self-efficacy' while behavioural change, according to Prochaska, is realised in a circular process consisting of precontemplation, contemplation, preparation, action and maintenance. ${ }^{72-74}$

In addition to repeating information regarding the benefits of physical activity during and after treatment (as per the Global Strategy on Diet, Physical Activity and Health $^{59}$ ), counselling sessions will incorporate the following aspects: (1) exploration of barriers and promoting of short-term and long-term adoption of adequate exercise levels ${ }^{75}$; (2) the experience of burdensome side effects, with special emphasis on uncovering unmet needs for medical support during phases of

Table 2 Home-based individual progressive pedometer intervention

\begin{tabular}{|c|c|c|c|c|c|c|c|}
\hline Week 1 & Week 2 & Week 4 & \multicolumn{2}{|c|}{ Week 6} & \multicolumn{2}{|l|}{ Week 9} & Week 12 \\
\hline $\begin{array}{l}\text { Establish } \\
\text { baseline level } \\
\text { Pedometer } \\
\text { instruction }\end{array}$ & $\begin{array}{l}\text { Planning of } \\
\text { pedometer use }\end{array}$ & $\begin{array}{l}\text { Pedometer } \\
\text { instruction and } \\
\text { evaluation }\end{array}$ & \multicolumn{2}{|c|}{$\begin{array}{l}\text { Pedometer } \\
\text { instruction and } \\
\text { evaluation }\end{array}$} & \multicolumn{2}{|c|}{$\begin{array}{l}\text { Telephone: pedometer } \\
\text { instruction and } \\
\text { evaluation }\end{array}$} & $\begin{array}{l}\text { Pedometer } \\
\text { instruction and } \\
\text { evaluation }\end{array}$ \\
\hline Baseline & & \multicolumn{2}{|l|}{ Week 6} & \multicolumn{2}{|l|}{ Week 12} & \multicolumn{2}{|c|}{ Week 39} \\
\hline \multicolumn{2}{|c|}{$\begin{array}{l}\text { Health counselling and } \\
\text { symptom management }(1 \mathrm{~h})\end{array}$} & \multicolumn{2}{|c|}{$\begin{array}{l}\text { Health counselling and } \\
\text { symptom management }(1 \mathrm{~h})\end{array}$} & \multicolumn{2}{|c|}{$\begin{array}{l}\text { Health counselling and } \\
\text { symptom management }(1 \mathrm{~h})\end{array}$} & \multicolumn{2}{|c|}{$\begin{array}{l}\text { Health counselling and } \\
\text { symptom management }(1 \mathrm{~h})\end{array}$} \\
\hline
\end{tabular}


chemotherapy; (3) anxiety, stress and stigma; ${ }^{43}$ (4) actual and post-treatment employment and social integration $^{76}$ and (5) healthy lifestyles (smoking cessation, dietary guidance, alcohol consumption), including information regarding municipality-based rehabilitation programmes. ${ }^{77}$ Health promotion counselling and symptom management will take place at baseline and during weeks 6,12 and 39 .

\section{Study arm 3}

Control group n=15: The control group will receive standard care with no restrictions regarding participation in physical activity. Patients allocated to the control group will be considered wait-list patients during the 12-week study period. Owing to ethical considerations and growing scientific evidence that exercise interventions benefit motivated patients with cancer and survivors in Denmark, ${ }^{51} 78$ the control patients will be offered participation in 'Body \& Cancer'. Time points for study assessments among control group patients will be on par with the intervention patients.

\section{Study goals and assessments}

Primary outcome $\mathrm{VO}_{2}$-peak

To determine $\mathrm{VO}_{2}$-peak, an incremental test on a cycle ergometer (Monark, ergomedic 839E) will be carried out by an exercise physiologist/physiotherapist. The test will consist of a warm-up phase lasting 4-10 min at a submaximal load $(30-80 \mathrm{~W})$. Once a steady state is achieved during warm-up (monitored by heart rate), the load will be increased following a short break $(<2 \mathrm{~min})$ by $5-20 \mathrm{~W}$ every minute until exhaustion or symptom limitation (eg, dizziness, sudden pain and vomiting sensation). Expired gases will be analysed continuously by a metabolic breath-by-breath analysis and calculated as an average over $15 \mathrm{~s}$ using the Oxycon Pro, Jaeger measurement system. During the $\mathrm{VO}_{2}$-peak test, oxyhaemoglobin saturation and heart rate will be continuously monitored. After each test, maximum ventilation, respiratory exchange ratio, plateau in the increase in $\mathrm{VO}_{2}$ and HRmax (Polar Team System 2, Polar, Finland) will be recorded. ${ }^{79-81}$ Self-perceived exertion will be evaluated using the modified Borg Scale (table 3). ${ }^{79}$

\section{Safety considerations}

The oncologists will have the overall responsibility for their respective patients' participation in the project. A clinical nurse specialist will screen patients before initiating any $\mathrm{VO}_{2}$-peak test. Pretest procedures will include an assessment of general well-being, infections (temperature raise higher than $38^{\circ} \mathrm{C}$, receiving antibiotics) and/ or irregularities in the cardiorespiratory circuit (resting blood pressure, resting heartbeat). Furthermore, haemoglobin will be measured using Hb201+ (HemoCue, Denmark), and haemoglobin levels below $5.5 \mathrm{mmol} / \mathrm{L}$ will disqualify patients from $\mathrm{VO}_{2}$-peak exercise testing. Finally, prior to the $\mathrm{VO}_{2}$-peak test, pulmonary function will be determined using standard spirometry in a standing position using the Oxycon Pro, Jaeger measurement system.

\section{Secondary outcomes}

PROs: PROs are assessed at baseline, 6, 12 and 39 weeks. PRO questionnaires will be coded according to questionnaire manuals. Procedures for data entry and audit have been developed to ensure data keying. ${ }^{82}$

The European Organisation for Research and Treatment of Cancer Quality of Life Questionnaire (EORTC QLQ-C30), ${ }^{83}$ comprises five functional scales, nine symptom scales or items and a global health status/ quality of life scale with additional breast cancer-specific EORTC BR23 ${ }^{84}$ and colon-rectal cancer-specific EORTC CR29. ${ }^{85}$ General well-being is assessed with the Medical Outcomes Study Short Form $36^{86}$ which contains eight scales measuring general health concepts and two summary scales: a physical component scale and a mental component scale.

The perception of pain will be measured on a weekly basis by the Brief Pain Inventory BPI. ${ }^{87}$

To assess psychological well-being, Hospital Anxiety and Depression Scale ${ }^{88}$ with 14 items will be administered, designed to measure general anxiety and depression for use in investigations in patients with physical illness. ${ }^{89} 90$

Leisure time physical activity level is explored by a questionnaire item classifying patients as: sedentary (completely inactive); walking or cycling for pleasure; regular physical exercise at least $3 \mathrm{~h}$ a week; or intense physical activity more than $4 \mathrm{~h}$ a week. ${ }^{81} 91$

PROs will also include validated questionnaires of motivational readiness and ability and barriers to engage in exercise activities 'stages of motivational readiness" 71 'decisional balance, 92 and 'exercise self-efficacy'. 71 Social support and network will be measured with 'The Multidimensional Scale of Perceived Social Support' ${ }^{93}$ Additional questionnaires will assess sociodemographic and lifestyle characteristics, workforce attachment and work ability. ${ }^{76}$

\section{Muscle strength}

Strength will be measured by the $1 \mathrm{RM}$ test. ${ }^{59}$ The tests will be performed on Technogym equipment (Gambettola, Italy) and will involve chest press; leg press, knee extension and latissimus pull down.

Pedometer: Total steps and aerobic steps will be measured using the Omron Walking Style Pro step counter.

\section{Body composition}

Fasting DXA scans will be performed at the Clinical Nuclear and Physiological Department of Copenhagen University Hospital (Rigshospitalet). Bone density, lean body mass, total muscle mass or fat mass is increasingly being used as a primary endpoint in health promotion intervention studies in healthy and clinical populations, including patients with prostate cancer ${ }^{94}$ and postmenopausal women with breast cancer. ${ }^{95}$ Fat mass has been shown to be directly associated with mortality; however, 
Table 3 Outcome parameters, methods and assessment time points

\begin{tabular}{|c|c|c|c|c|c|}
\hline Outcome parameters & Methods & $\begin{array}{l}\text { Baseline } \\
\text { test }\end{array}$ & $\begin{array}{l}\text { 6-Week } \\
\text { test }\end{array}$ & $\begin{array}{l}\text { 12-Week } \\
\text { test }\end{array}$ & $\begin{array}{l}\text { 39-Week } \\
\text { test }\end{array}$ \\
\hline \multicolumn{6}{|l|}{ Primary outcome } \\
\hline \multirow[t]{2}{*}{ Physical capacity/oxygen uptake } & $\begin{array}{l}\text { Maximal oxygen uptake }\left(\mathrm{VO}_{2} \text { peak). }\right. \\
\text { Incremental test on a cycle ergometer }{ }^{95115}\end{array}$ & $x$ & $x$ & $x$ & $x$ \\
\hline & $\begin{array}{l}\text { Assessment of physical exertion at } \\
\text { physiological tests on the BORG scale }\end{array}$ & $x$ & $\mathrm{x}$ & $x$ & $x$ \\
\hline \multicolumn{6}{|l|}{ Secondary physiological outcomes } \\
\hline Maximum muscle strength & $\begin{array}{l}\text { One-repetition maximum tests (1 RM } \\
\text { test) }\end{array}$ & $x$ & $\mathrm{x}$ & $x$ & $\mathrm{x}$ \\
\hline $\begin{array}{l}\text { Body composition (bone density, } \\
\text { muscle and fat mass) }\end{array}$ & DXA $\operatorname{scan}^{104105}$ & $x$ & & $x$ & $x$ \\
\hline $\begin{array}{l}\text { Physical activity (objective } \\
\text { measurement) }\end{array}$ & Pedometer. Omron Walking Style Pro ${ }^{20}$ & $x$ & $x$ & $x$ & \\
\hline Body mass index (BMI) & Height and weight & $x$ & $x$ & $x$ & $x$ \\
\hline Biomarkers & $\begin{array}{l}\text { Lipids, cholesterols, blood glucose, } \\
\text { insulin }^{109}\end{array}$ & $x$ & & $x$ & $x$ \\
\hline Pulse & $\begin{array}{l}\text { Pulse sensor during hospital-based } \\
\text { exercise intervention }\end{array}$ & $x$ & $x$ & $x$ & \\
\hline Blood pressure/pulse & Test blood pressure+test pulse & $x$ & $x$ & $x$ & \\
\hline \multicolumn{6}{|l|}{ Secondary psycometric outcomes } \\
\hline $\begin{array}{l}\text { Self-reported leisure time physical } \\
\text { activity }\end{array}$ & $\begin{array}{l}\text { (1) Self-reported participation in physical } \\
\text { leisure activity } \pm 150 \mathrm{~min} / \text { week and at least } \\
20 \text { min strenuous workouts twice weekly } \\
\text { assessed in the past week* (Danish } \\
\text { national recommendations) }\end{array}$ & $\mathrm{x}^{*}$ & $x$ & $x$ & $x$ \\
\hline $\begin{array}{l}\text { Questionnaire 1: Motivational } \\
\text { readiness }\end{array}$ & $\begin{array}{l}\text { Stages of motivational readiness } \\
\text { Decisional balance } \\
\text { De2 }\end{array}$ & $x$ & $\mathrm{x}$ & $\mathrm{x}$ & $\mathrm{x}$ \\
\hline $\begin{array}{l}\text { Benefits and barriers to exercise } \\
\text { Ability to engage in exercise }\end{array}$ & Exercise self-efficacy ${ }^{6687}$ & & & & \\
\hline Questionnaire 2: General well-being & $\begin{array}{l}\text { Medical Outcomes Study Short Form MOS } \\
\text { SF }-36^{63}\end{array}$ & $x$ & $x$ & $x$ & $x$ \\
\hline $\begin{array}{l}\text { Questionnaire 3: Anxiety and } \\
\text { depression }\end{array}$ & $\begin{array}{l}\text { The Hospital Anxiety and Depression } \\
\text { Scale/HADS }\end{array}$ & $\mathrm{x}$ & $x$ & $x$ & $x$ \\
\hline $\begin{array}{l}\text { Questionnaire 4: Health-related quality } \\
\text { of life }\end{array}$ & $\begin{array}{l}\text { European Organization for Research and } \\
\text { Treatment of Cancer Quality of Life } \\
\text { Questionnaire/EORTC QLQ-C30 } 30^{116}+ \\
\text { BR23 }^{61}+\text { CR2962 }\end{array}$ & $x$ & $x$ & $x$ & $x$ \\
\hline $\begin{array}{l}\text { Questionnaire 5: Social support and } \\
\text { network }\end{array}$ & $\begin{array}{l}\text { Multidimensional Scale of Perceived Social } \\
\text { Support MSPSS }^{103}\end{array}$ & $x$ & & $x$ & $\mathrm{x}$ \\
\hline Supplemental questionnaire 6 : & Bengt Saltin "Leisure Time Physical Activity & $x$ & $\mathrm{x}$ & $\mathrm{x}$ & $x$ \\
\hline $\begin{array}{l}\text { Physical activity/categorical labour, } \\
\text { disability, participation in local } \\
\text { rehabilitation lifestyle factors (smoking } \\
\text { cessation, alcohol, diet) }\end{array}$ & $\begin{array}{l}\text { Scale"117 Selected questions from the } \\
\text { questionnaire on "issues relating. work for } \\
\text { people who have been diagnosed with } \\
\text { cancer" Finn Diderichsen IFV University of } \\
\text { Copenhagen }\end{array}$ & & & & \\
\hline $\begin{array}{l}\text { Other disease, treatment and cancer } \\
\text { related outcomes: }\end{array}$ & Register and Patient Medical Record Data & & & & \\
\hline Comorbidity & $\begin{array}{l}\text { Charlsons Comorbidity Index } \\
\text { Cardiovascular and musculoskeletal } \\
\text { disease }\end{array}$ & $\mathrm{x}$ & & & $\mathrm{x}$ \\
\hline $\begin{array}{l}\text { Disease-free survival and relapse } \\
\text { chemotherapy completion rate }\end{array}$ & $\begin{array}{l}\text { Patient Medical Record Data (electronic } \\
\text { form) }\end{array}$ & $\mathrm{x}$ & $x$ & $x$ & $x$ \\
\hline Performance status & WHO/ECOG performance scale ${ }^{118}$ & $x$ & $\mathrm{x}$ & $\mathrm{x}$ & $x$ \\
\hline
\end{tabular}

this may be counteracted by the skeletal muscles as an active organ that prevents negative health effects of fat. ${ }^{96} 97$ Previous studies have predominantly used body mass index, however, recent studies clearly show that a more detailed assessment of body composition is required for investigating overall health effects. ${ }^{96} 98$ 


\section{Blood markers}

Blood markers including fasting glucose, insulin, cholesterols (high-density lipoprotein, low-density lipoprotein) and triglyceride will be drawn to assess long-term metabolic cardiovascular risks. ${ }^{99}$

\section{Cancer disease characteristics, morbidity and comorbidities}

Detailed clinical information concerning cancer disease characteristics, morbidity and comorbidities, hospital admissions and medical supportive care needs are obtained by clinical nurse specialists from electronic medical records.

\section{Chemotherapy completion rate}

Based on medical record entries, information regarding dosage, type and timing of chemotherapy administration will be obtained for each patient, including the use of neutrophils colony stimulating factor (Neulasta), antiemetics and analgesics. Chemotherapy completion rate will be measured throughout the planned period of treatment and beyond the 12-week intervention time frame. This includes observed time intervals between cycles of chemotherapy, planned doses of administered drugs and the overall conduct of scheduled treatments.

\section{Qualitative investigation and methods}

Qualitative, semistructured hermeneutic-phenomenological interviews will be held with 15 patients from each of the study groups, during weeks 12 and 39. These interviews will highlight patients' perspectives about their adaptation to and adoption of, increased physical activity in their daily lives and while undergoing chemotherapy. Exercise habits before cancer diagnosis as well as prior to joining the study will be discussed, as will the patients' views and experiences with the 12-week intervention. The rationale for absenteeism and/or decision for non-participation in the intervention, including barriers to the same, will be explored as well as physical or/and emotional reactions experienced by the patients during the intervention (discomfort, adverse reactions). In addition, physical, emotional and social barriers that impacted sustaining lifestyle changes will be in focus. Not in the least, the intervention's potential impact on patient decisions to return to the workforce and/or rekindle their social relationships will be discussed. The semistructured interview will be used for monitoring purposes as well as for making adjustments to the exercise components.

\section{Tracking and monitoring adverse events}

Pre-exercise screening is routinely performed by a clinical nurse specialist before every training session in order to ensure safety and to pay attention to specific symptoms and side-effects experienced by patients during the high-intensity intervention (ie, dizziness, retching and balance problems). Furthermore, patients are advised and guided to respect their own physical limitations. Specific case report forms are developed to monitor adverse events related to programme participation that subsequently may interfere with chemotherapy adherence or exclude patients from engaging in the intervention and/or daily living activities (eg, musculoskeletal injuries).

Serious adverse events will immediately be reported to the Regional Scientific Committee of the Capital Region and The Danish National Board of Health in accordance with existing legislation. In addition, serious adverse events will immediately be circulated to all research group members for discussion in order to execute a response prior to continuing any testing and/ or intervention activities.

\section{Ethical considerations}

In Denmark, there are currently no 12-week hospital or home-based exercise programmes that are routinely offered to patients with colon or breast cancer undergoing adjuvant chemotherapy. Thus no patient will be prevented from accepting the best possible treatment as a complement to adjuvant chemotherapy, or in any way be omitted from receiving the most relevant treatment. Patients who decline participation in the feasibility study can increase their levels of physical activity on par with people who frequent fitness or sports clubs and can participate in municipality-led rehabilitation programmes with a referral from their attending physicians.

The DXA scan exposes patients to weak x-rays (radiation) equivalent to the background radiation ( 0.01 milliSievert) that an average person is exposed to during 3 days, and is comparable to $1 / 10$ th of exposure in the case of a chest $\mathrm{X}$-ray. The increased risk as such is calculated in units per thousand and is not considered to be dangerous. ${ }^{88}$

\section{Approvals and registration}

The project is approved by the Danish Data Protection Agency (j.nr.2011-41-6349) and by the Scientific Committee of the Capital Region (case nr. H-1-2011-131). The feasibility study is registered as a current controlled trial (ISRCTN24901641) and will furthermore be published in accordance with the CONSORT guidelines for RCT publishing. ${ }^{100}$

\section{Analytic plan}

\section{Quantitative analyses}

The RCT feasibility design is selected in order to examine barriers for recruitment, programme adherence, safety aspects and potential efficacy related to study group allocation and intervention activities for patients with breast or colon cancer referred to adjuvant chemotherapy. Furthermore, quantitative and qualitative findings from the feasibility study may be used to adjust programme components and to determine important primary and secondary outcomes of interest. Results and potential effects along with existing exercise literature during chemotherapy will serve as a basis for power calculations prior to the planned RCT.

The principal analysis of primary and secondary outcomes will employ the intention-to-treat approach and 
as such will include all available data. Study group assignments will be maintained during the comparison of potential interventional effects. The explorative aspect may include statistical analysis across study groups in order to provide insight into mean values, SD, SD of change scores and the potential application of objective measurement tools and standardised PRO instruments in these patient populations.

\section{Qualitative analytic plan}

Patients will be asked for their written consent to be interviewed. All interviews will be tape-recorded and transcribed and the data will remain anonymous. The analysis, which will be inductive and thematic, relates to key theories in behaviour modification and control ${ }^{23} 74101$ as well as self-efficacy ${ }^{69}$ and social exclusion, inspired by Goffman ${ }^{102}$ and Giddens. ${ }^{103}$ It is assumed that $15-20$ patients per group will suffice to achieve the data saturation point. ${ }^{104}$

\section{DISCUSSION}

Cardiorespiratory fitness (CRF) is recognised as being an independent and important health-related component for metabolic coronary heart disease risk outcomes and long-term survival in both asymptomatic low-risk populations as well as in high-risk sedentary populations. ${ }^{105-107}$ In previous research, we have shown that a comprehensive high-low component exercise intervention may be necessary to improve CRF with derived positive impact on patient reported fatigue, hypothetically driven by linear improvement in vitality. ${ }^{51}$ As such, it assumes a causal connection with patients with cancer respective physical activity levels and a potentially strong interaction with physiological and psychological outcomes. $^{108} 109$ Thus, CRF measured as $\mathrm{VO}_{2}$-peak has been selected as the primary outcome in the present RCT feasibility study. To ensure valid and high-quality methods, cycle ergometer testing and direct continuous measurement of respiratory gas exchange will be used to estimate the interventional effects on CRF. Further on, we will be able to detect important gradients in walking and exercise behaviour by examining the efficacy of patients wearing Omron pedometers. These pedometers are able to monitor and record step data on daily, weekly and monthly basis in accordance with individual goals for physical activity.

With respect to exercise interventions during cancer treatment, CRF has been one of the dominant outcomes, despite the fact that only $29 \%$ of RCTs demonstrated significant benefit on aerobic capacity, according to a systematic review and meta-analysis by Speck et $a l^{25}$ The term 'during cancer treatment' represents a comprehensive range of distinct treatment modalities (eg, surgery, chemotherapy, radiotherapy, targeted antibodies and antihormones), that each, along with their respective side effects, may impact patient life experiences and ability to cope. Undergoing chemotherapy is commonly considered to be harmful to physiological functioning and capacity ${ }^{27} 110$ produces toxic side effects, ${ }^{6} 13$ 111-113 impacts general wellbeing and causes psychological distress. ${ }^{20} 114115$ Though a considerable amount of studies have been performed in the breast cancer population, few RCTs have been conducted during chemotherapy and with different primary outcomes (fatigue, weight gain, quality of life, bone density, physiological capacity and patient reported physical functioning). ${ }^{116-120}$ Exercise interventions during chemotherapy that consider patients with colon cancer represent a total gap in the field. ${ }^{24}$

The question of optimal timing for exercise instigation is relevant to discuss and it is still unclear how soon after diagnosis exercise should be promoted. ${ }^{24} 40$ This is particularly relevant in the case of patients with cancer who undergo invasive surgery often followed by chemotherapy. Furthermore, these patients' physical habitués, comorbidity and symptom and side effects burden may influence their ability to participate in exercise interventions irrespective of motivational factors. This is even more pertinent among patients with breast and colon cancers, as adjuvant chemotherapy regimens, administered in the outpatient clinic, are standardised to incorporate a variety of antineoplastic agents, with specific individual toxicities. However, patient-professional time in the outpatient setting to support symptom management may be limited.

Identifying sedentary patients and measuring physical activity levels presents numerous challenges. Different self-report methods are applied across studies ${ }^{121} 122$ and may increase the risk of inaccurate or biased recall of physical activities and training intensities. The challenge is therefore to identify, recruit and motivate a sedentary population by using national criteria for physical inactivity, which remains a central element for discussion and validation in the current feasibility study.

In parallel, it is a constant challenge for cancer survivors to take initiative to remain active and adopt exercise as a behavioural practice in daily life following adjuvant chemotherapy. ${ }^{78} 123$ Results from the USA show that $35 \%$ of cancer survivors remain physically inactive 5 years after diagnosis. ${ }^{124}$ No such data are currently available in Danish populations.

The present feasibility study incorporates 45 sedentary patients identified by oncologists and clinical nurses during prescreening in the department of oncology. We hypothesise that the onset period of adjuvant chemotherapy can be 'the open window of opportunity' to identify and motivate sedentary patients with breast and colon cancers to initiate and sustain lifestyle changes of importance to their health.

This feasibility study will provide insight into shortterm core clinical benefits (eg, symptom management, treatment adherence and completion) and individual barriers to exercise during adjuvant chemotherapy while simultaneously scoping long-term health and social benefits of two exercise interventions. 
Author affiliations

${ }^{1}$ Department of Rigshospitalet, The University Hospitals Centre for Health Care Research UCSF Copenhagen University Hospital, Copenhagen, Denmark ${ }^{2}$ Department of Oncology, Copenhagen University Hospital Rigshospitalet, Copenhagen, Denmark

${ }^{3}$ Faculty of Health, Institute of Public Health, The University of Copenhagen, Copenhagen, Denmark

Contributors TM and LA are the principal investigators who designed the study and drafted the article. CL, TM, KBC and CA will be conducting the exercise intervention. $B E, L N$ and $E V$ are the responsible oncologists. $K B C$ is the trial statistician and responsible for statistic evaluation. All authors have made substantial contributions to conception and design of the project and all authors approved the final manuscript.

Funding The project is part of The Center for Integrated Rehabilitation of Cancer Patients Copenhagen Denmark CIRE, a centre established and supported by The Danish Cancer Society and The Novo Nordic Foundation. Furthermore, the project has received grants from Trygfonden Denmark.

Competing interests None.

Ethics approval The Scientific Committee of the Capital Region (case No. H-1-2011-131) and the Danish Data Protection Agency (j. No. 2011-41-6349).

Provenance and peer review Not commissioned; externally peer reviewed.

Data sharing statement Data will be entered into the CIRE-Database hosted by the Copenhagen Trial Unit, who exclusively has unlimited access to data.

Open Access This is an Open Access article distributed in accordance with the Creative Commons Attribution Non Commercial (CC BY-NC 3.0) license, which permits others to distribute, remix, adapt, build upon this work noncommercially, and license their derivative works on different terms, provided the original work is properly cited and the use is non-commercial. See: http:// creativecommons.org/licenses/by-nc/3.0/

\section{REFERENCES}

1. Statens Seruminstitut. Cancerregistret: tal og analyser 2011 [The Danish Cancer Registry: figures and analysis 2011]. Copenhagen: SSI, 2012.

2. Storm $\mathrm{HH}$, Engholm G, Hakulinen T, et al. Survival of patients diagnosed with cancer in the Nordic countries up to 1999-2003 followed to the end of 2006: a critical overview of the results. Acta Oncol 2010;49:532-44.

3. Andersen $\mathrm{KG}$, Jensen $\mathrm{MB}$, Kehlet $\mathrm{H}$, et al. Persistent pain, sensory disturbances and functional impairment after adjuvant chemotherapy for breast cancer: cyclophosphamide, epirubicin and fluorouracil compared with docetaxel + epirubicin and cyclophosphamide. Acta Oncol 2012;51:1036-44.

4. Andersen KG, Kehlet $\mathrm{H}$. Persistent pain after breast cancer treatment: a critical review of risk factors and strategies for prevention. J Pain 2011;12:725-46.

5. Eckhoff L, Nielsen M, Moeller S, et al. TAX. Acta Oncol 2011;50:1075-82.

6. Saibil S, Fitzgerald B, Freedman OC, et al. Incidence of taxane-induced pain and distress in patients receiving chemotherapy for early-stage breast cancer: a retrospective, outcomes-based survey. Curr Oncol 2010;17:42-7.

7. Kangas $\mathrm{M}$, Bovbjerg $\mathrm{DH}$, Montgomery $\mathrm{GH}$. Cancer-related fatigue: a systematic and meta-analytic review of non-pharmacological therapies for cancer patients. Psychol Bull 2008;134:700-41.

8. Mock V, Atkinson A, Barsevick A, et al. NCCN Practice Guidelines for cancer-related fatigue. Oncology (Williston Park) 2000;14 (11A):151-61.

9. Stasi R, Abriani L, Beccaglia P, et al. Cancer-related fatigue: evolving concepts in evaluation and treatment. Cancer 2003:98:1786-801.

10. Velthuis MJ, Agasi-Idenburg SC, Aufdemkampe G, et al. The effect of physical exercise on cancer-related fatigue during cancer treatment: a meta-analysis of randomised controlled trials. Clin Oncol (R Coll Radiol) 2010;22:208-21.

11. Navari RM. Pharmacological management of chemotherapy-induced nausea and vomiting: focus on recent developments. Drugs 2009;69:515-33.
12. Navari RM. Management of chemotherapy-induced nausea and vomiting: focus on newer agents and new uses for older agents. Drugs 2013;73:249-62.

13. Vance V, Mourtzakis M, McCargar L, et al. Weight gain in breast cancer survivors: prevalence, pattern and health consequences. Obes Rev 2011:12:282-94.

14. Demark-Wahnefried W, Peterson BL, Winer EP, et al. Changes in weight, body composition, and factors influencing energy balance among premenopausal breast cancer patients receiving adjuvant chemotherapy. J Clin Oncol 2001;19:2381-9.

15. Allegra CJ, Yothers G, O'Connell MJ, et al. Initial safety report of NSABP C-08: A randomized phase III study of modified FOLFOX6 with or without bevacizumab for the adjuvant treatment of patients with stage II or III colon cancer. J Clin Oncol 2009;27:3385-90.

16. Qin YY, Li H, Guo XJ, et al. Adjuvant chemotherapy, with or without taxanes, in early or operable breast cancer: a meta-analysis of 19 randomized trials with 30698 patients. PLoS ONE 2011;6:e26946.

17. Brain $E$, Levy $C$, Serin $D$, et al. High rate of extra-haematological toxicity compromises dose-dense sequential adjuvant chemotherapy for breast cancer. Br J Cancer 2011;105:1480-6.

18. Moebus V, Jackisch C, Lueck HJ, et al. Intense dose-dense sequential chemotherapy with epirubicin, paclitaxel, and cyclophosphamide compared with conventionally scheduled chemotherapy in high-risk primary breast cancer: mature results of an AGO phase III study. J Clin Oncol 2010;28:2874-80.

19. Midtgaard J, Baadsgaard MT, Moller T, et al. Self-reported physical activity behaviour; exercise motivation and information among Danish adult cancer patients undergoing chemotherapy. Eur $J$ Oncol Nurs 2009;13:116-21.

20. Breen SJ, Baravelli CM, Schofield PE, et al. Is symptom burden a predictor of anxiety and depression in patients with cancer about to commence chemotherapy? Med J Aust 2009;190(Suppl 7): S99-104.

21. Zabora J, BrintzenhofeSzoc K, Curbow B, et al. The prevalence of psychological distress by cancer site. Psychooncology 2001:10:19-28.

22. Cleeland CS. Symptom burden: multiple symptoms and their impact as patient-reported outcomes. J Natl Cancer Inst Monogr 2007;37:16-21.

23. Pinto BM, Eakin E, Maruyama NC. Health behavior changes after a cancer diagnosis: what do we know and where do we go from here? Ann Behav Med 2000;22:38-52.

24. Schmitz KH, Courneya KS, Matthews C, et al. American College of Sports Medicine roundtable on exercise guidelines for cancer survivors. Med Sci Sports Exerc 2010;42:1409-26.

25. Speck RM, Courneya KS, Masse LC, et al. An update of controlled physical activity trials in cancer survivors: a systematic review and meta-analysis. J Cancer Surviv 2010;4:87-100.

26. Jones LW, Alfano CM. Exercise-oncology research: past, present, and future. Acta Oncol 2013;52:195-215.

27. Mishra SI, Scherer RW, Snyder C, et al. Exercise interventions on health-related quality of life for people with cancer during active treatment. Clin Otolaryngol 2012;37:390-2.

28. Mishra SI, Scherer RW, Snyder C, et al. Exercise interventions on health-related quality of life for people with cancer during active treatment. Cochrane Database Syst Rev 2012;(8):CD008465.

29. Friedenreich CM, Gregory J, Kopciuk KA, et al. Prospective cohort study of lifetime physical activity and breast cancer survival. Int $J$ Cancer 2009;124:1954-62.

30. Giovannucci E. Modifiable risk factors for colon cancer. Gastroenterol Clin North Am 2002;31:925-43.

31. Holmes MD, Chen WY, Feskanich D, et al. Physical activity and survival after breast cancer diagnosis. JAMA 2005;293:2479-86.

32. Meyerhardt JA, Giovannucci EL, Holmes MD, et al. Physical activity and survival after colorectal cancer diagnosis. $J$ Clin Oncol 2006:24:3527-34.

33. Hawkes AL, Lynch BM, Owen N, et al. Lifestyle factors associated concurrently and prospectively with co-morbid cardiovascular disease in a population-based cohort of colorectal cancer survivors. Eur J Cancer 2011;47:267-76.

34. Herman DR, Ganz PA, Petersen L, et al. Obesity and cardiovascular risk factors in younger breast cancer survivors: the Cancer and Menopause Study (CAMS). Breast Cancer Res Treat 2005;93:13-23.

35. Jones LW, Haykowsky MJ, Swartz JJ, et al. Early breast cancer therapy and cardiovascular injury. J Am Coll Cardiol 2007;50:1435-41.

36. Lenihan DJ, Cardinale D, Cipolla CM. The compelling need for a cardiology and oncology partnership and the birth of the International CardiOncology Society. Prog Cardiovasc Dis 2010;53:88-93. 
37. Mann DL, Krone RJ. Cardiac disease in cancer patients: an overview. Prog Cardiovasc Dis 2010;53:80-7.

38. Schmitz KH, Prosnitz RG, Schwartz AL, et al. Prospective surveillance and management of cardiac toxicity and health in breast cancer survivors. Cancer 2012;118(8 Suppl):2270-6.

39. Velthuis MJ, May AM, Koppejan-Rensenbrink RA, et al. Physical Activity during Cancer Treatment (PACT) Study: design of a randomised clinical trial. BMC Cancer 2010;10:272.

40. Demark-Wahnefried W, Aziz NM, Rowland JH, et al. Riding the crest of the teachable moment: promoting long-term health after the diagnosis of cancer. J Clin Oncol 2005;23:5814-30.

41. Pinto BM, Maruyama NC, Clark MM, et al. Motivation to modify lifestyle risk behaviors in women treated for breast cancer. Mayo Clin Proc 2002;77:122-9.

42. Jones LW, Courneya KS, Peddle C, et al. Oncologists' opinions towards recommending exercise to patients with cancer: a Canadian national survey. Support Care Cancer 2005;13:929-37.

43. Adamsen L, Andersen C, Midtgaard J, et al. Struggling with cancer and treatment: young athletes recapture body control and identity through exercise: qualitative findings from a supervised group exercise program in cancer patients of mixed gender undergoing chemotherapy. Scand J Med Sci Sports 2009;19:55-66.

44. Jarden M, Nelausen K, Hovgaard D, et al. The effect of a multimodal intervention on treatment-related symptoms in patients undergoing hematopoietic stem cell transplantation: a randomized controlled trial. J Pain Symptom Manage 2009;38:174-90.

45. Midtgaard J, Rorth M, Stelter R, et al. The group matters: an explorative study of group cohesion and quality of life in cancer patients participating in physical exercise intervention during treatment. Eur J Cancer Care (Engl) 2006;15:25-33.

46. Midtgaard J, Stelter R, Rorth $M$, et al. Regaining a sense of agency and shared self-reliance: the experience of advanced disease cancer patients participating in a multidimensional exercise intervention while undergoing chemotherapy: analysis of patient diaries. Scand J Psychol 2007;48:181-90.

47. Moller T, Adamsen L. Hematologic patients' clinical and psychosocial experiences with implanted long-term central venous catheter: self-management versus professionally controlled care. Cancer Nurs 2010;33:426-35.

48. Danish Health and Medicines Authority. Physical activity: recommendations for adults (18-64 years old). 2013. [cited 2013 July 3]. http://www.sst.dk/English/Health_promotion/Physical_ activity/Recommendations for adults.aspx

49. Danish Breast Cancer Cooperative Group. Randomized trial of epirubicin and cyclophosphamide followed by docetaxel against docetaxel and cyclophosphamide in patients with TOP2A normal early breast cancer. 2009. [cited 2013 July 3]. http://www.dbcg.dk/ PDF\%20Filer/07-READ\%20Prtotokol\%20161009.pdf

50. Cassidy J. SCOT-Short Course Oncology Therapy: a study of adjuvant chemotherapy in colorectal cancer by the CACTUS and QUASAR 3 Groups: RCTN59757862. 2013. [cited 2013 July 3]. http://www.controlled-trials.com/ISRCTN59757862

51. Adamsen L, Quist M, Andersen C, et al. Effect of a multimodal high intensity exercise intervention in cancer patients undergoing chemotherapy: randomised controlled trial. BMJ 2009;339:b3410.

52. Jones LW, Eves ND, Haykowsky M, et al. Cardiorespiratory exercise testing in clinical oncology research: systematic review and practice recommendations. Lancet Oncol 2008;9:757-65.

53. Leitzmann MF, Park Y, Blair A, et al. Physical activity recommendations and decreased risk of mortality. Arch Intern Med 2007;167:2453-60.

54. De Vries HA. Exercise intensity threshold for improvement of cardiovascular-respiratory function in older men. Geriatrics 1971;26:94-101.

55. Nordesjo LO. The effect of quantitated training on the capacity for short and prolonged work. Acta Physiol Scand Suppl 1974;405:1-54.

56. Davies CT, Knibbs AV. The training stimulus. The effects of intensity, duration and frequency of effort on maximum aerobic power output. Int Z Angew Physiol 1971;29:299-305.

57. Shephard RJ. Intensity, duration and frequency of exercise as determinants of the response to a training regime. Int $Z$ Angew Physiol 1968;26:272-8.

58. Adamsen L, Midtgaard J, Rorth M, et al. Feasibility, physical capacity, and health benefits of a multidimensional exercise program for cancer patients undergoing chemotherapy. Support Care Cancer 2003;11:707-16.

59. World Health Organization. Global strategy on diet, physical activity and health: physical activity and adults: recommended levels of physical activity for adults aged 18-64 years. 2011. http://www. who.int/dietphysicalactivity/factsheet_adults/en/index.htm/
60. Kwekkeboom KL, Hau H, Wanta B, et al. Patients' perceptions of the effectiveness of guided imagery and progressive muscle relaxation interventions used for cancer pain. Complement Ther Clin Pract 2008;14:185-94.

61. Luebbert K, Dahme B, Hasenbring M. The effectiveness of relaxation training in reducing treatment-related symptoms and improving emotional adjustment in acute non-surgical cancer treatment: a meta-analytical review. Psychooncology 2001:10:490-502.

62. Ferrell-Torry AT, Glick OJ. The use of therapeutic massage as a nursing intervention to modify anxiety and the perception of cancer pain. Cancer Nurs 1993;16:93-101.

63. Krustrup P, Hansen PR, Andersen LJ, et al. Long-term musculoskeletal and cardiac health effects of recreational footbal and running for premenopausal women. Scand J Med Sci Sports 2010;20(Suppl 1):58-71.

64. Krustrup P, Christensen JF, Randers MB, et al. Muscle adaptations and performance enhancements of soccer training for untrained men. Eur J Appl Physiol 2010;108:1247-58.

65. Krustrup P, Hansen PR, Randers MB, et al. Beneficial effects of recreational football on the cardiovascular risk profile in untrained premenopausal women. Scand J Med Sci Sports 2010;20( Suppl 1):40-9.

66. Pollock ML, Gaesser GA, Butcher JD, et al. American College of Sports Medicine Position Stand. The recommended quantity and quality of exercise for developing and maintaining cardiorespiratory and muscular fitness, and flexibility in healthy adults. Med $\mathrm{Sci}$ Sports Exerc 1998;30:975-91.

67. Ainsworth BE, Haskell WL, Whitt MC, et al. Compendium of physical activities: an update of activity codes and MET intensities. Med Sci Sports Exerc 2000;32(Suppl 9):S498-504.

68. Klarlund Petersen B. Skridttællerprogrammet [The walk-up programme]. 2008. . http://www.walk-up.dk/inspiration/ skridttaelleren/13-skridttaellerprogrammet

69. Bandura A. Self-efficacy: toward a unifying theory of behavioral change. Psychol Rev 1977;84:191-215.

70. Bandura A. Social cognitive theory: an agentic perspective. Annual Rev Psychol 2001;52:1-26.

71. Marcus $\mathrm{BH}$, Rakowski W, Rossi JS. Assessing motivational readiness and decision making for exercise. Health Psychol 1992;11:257-61.

72. Marcus BH, Selby VC, Niaura RS, et al. Self-efficacy and the stages of exercise behavior change. Res $Q$ Exerc Sport 1992;63:60-6.

73. Marcus BH, Banspach SW, Lefebvre RC, et al. Using the stages of change model to increase the adoption of physical activity among community participants. Am J Health Promot 1992;6:424-9.

74. Prochaska JO, Norcross JC. Stages of change. Psychotherapy 2001;38:443-8.

75. Courneya KS, McKenzie DC, Reid RD, et al. Barriers to supervised exercise training in a randomized controlled trial of breast cancer patients receiving chemotherapy. Ann Behav Med 2008;35: 116-22.

76. Carlsen K, Dalton SO, Diderichsen F, et al. Risk for unemployment of cancer survivors: a Danish cohort study. Eur J Cancer 2008;44:1866-74

77. Tønnesen H, Søndergaard L, Jørgensen $\mathrm{T}$, et al. Terminologi: forebyggelse, sundhedsfremme og folkesundhed [Terminology: prevention, health promotion and public health]. Copenhagen: National Board of Health, 2005.

78. Midtgaard J, Christensen JF, Tolver A, et al. Efficacy of multimodal exercise-based rehabilitation on physical activity, cardiorespiratory fitness, and patient-reported outcomes in cancer survivors: a randomized, controlled trial. Ann Oncol 2013;24:2267-73.

79. Borg G. Perceived exertion as an indicator of somatic stress. Scand J Rehabil Med 1970;2:92-8.

80. Fairshter RD, Walters J, Salness K, et al. A comparison of incremental exercise tests during cycle and treadmill ergometry. Med Sci Sports Exerc 1983;15:549-54.

81. Saltin B, Astrand PO. Maximal oxygen uptake in athletes. J Appl Physiol 1967;23:353-8.

82. Buchele G, Och B, Bolte G, et al. Single vs. double data entry. Epidemiology 2005;16:130-1.

83. Aaronson NK, Ahmedzai S, Bergman B, et al. The European Organization for Research and Treatment of Cancer QLQ-C30: a quality-of-life instrument for use in international clinical trials in oncology. J Natl Cancer Inst 1993;85:365-76.

84. Sprangers MA, Groenvold M, Arraras Jl, et al. The European Organization for Research and Treatment of Cancer breast cancer-specific quality-of-life questionnaire module: first results from a three-country field study. J Clin Oncol 1996;14:2756-68. 
85. Whistance RN, Conroy $\mathrm{T}$, Chie $\mathrm{W}$, et al. Clinical and psychometric validation of the EORTC QLQ-CR29 questionnaire module to assess health-related quality of life in patients with colorectal cancer. Eur J Cancer 2009;45:3017-26.

86. Ware JE Jr, Sherbourne CD. The MOS 36-item short-form health survey (SF-36). I. Conceptual framework and item selection. Med Care 1992;30:473-83.

87. Cleeland CS, Ryan KM. Pain assessment: global use of the Brief Pain Inventory. Ann Acad Med Singapore 1994;23:129-38.

88. Zigmond AS, Snaith RP. The hospital anxiety and depression scale. Acta Psychiatr Scand 1983;67:361-70.

89. Bjelland I, Dahl AA, Haug TT, et al. The validity of the Hospital Anxiety and Depression Scale. An updated literature review. $J$ Psychosom Res 2002;52:69-77.

90. Snaith P. Anhedonia: exclusion from the pleasure dome. BM 1992;305:134

91. Aadahl M, Jorgensen T. Validation of a new self-report instrument for measuring physical activity. Med Sci Sports Exerc 2003;35:1196-202.

92. Marcus BH, Rossi JS, Selby VC, et al. The stages and processes of exercise adoption and maintenance in a worksite sample. Health Psychol 1992;11:386-95.

93. Dahlem NW, Zimet GD, Walker RR. The Multidimensional Scale of Perceived Social Support: a confirmation study. J Clin Psychol 1991;47:756-61.

94. Galvao DA, Taaffe DR, Spry N, et al. Combined resistance and aerobic exercise program reverses muscle loss in men undergoing androgen suppression therapy for prostate cancer without bone metastases: a randomized controlled trial. J Clin Oncol 2010;28:340-7.

95. Winters-Stone KM, Dobek J, Nail L, et al. Strength training stops bone loss and builds muscle in postmenopausal breast cancer survivors: a randomized, controlled trial. Breast Cancer Res Treat 2011;127:447-56

96. Pedersen BK. Body mass index-independent effect of fitness and physical activity for all-cause mortality. Scand J Med Sci Sports 2007;17:196-204.

97. Pedersen BK. Exercise-induced myokines and their role in chronic diseases. Brain Behav Immun 2011;25:811-16.

98. Pischon T, Boeing H, Hoffmann K, et al. General and abdominal adiposity and risk of death in Europe. $N$ Engl $\mathrm{J} \mathrm{Med}$ 2008;359:2105-20.

99. Nordestgaard BG, Zacho J. Lipids, atherosclerosis and CVD risk: is CRP an innocent bystander? Nutr Metab Cardiovasc Dis 2009;19:521-4.

100. Turner L, Shamseer L, Altman DG, et al. Consolidated standards of reporting trials (CONSORT) and the completeness of reporting of randomised controlled trials (RCTs) published in medical journals. Cochrane Database Syst Rev 2012;(11):MR000030.

101. Ajzen I. The theory of planned behaviour: reactions and reflections. Psychol Health 2011;26:1113-27.

102. Goffman E. Stigma: notes on the management of spoiled identity New York: Simon \& Schuster, 1986.

103. Giddens A. Modernity and self-identity: self and society in the late modern age. Cambridge: Polity Press, 1991.

104. Malterud K. Qualitative research: standards, challenges, and guidelines. Lancet 2001;358:483-8.

105. Barlow CE, Defina LF, Radford NB, et al. Cardiorespiratory fitness and long-term survival in 'low-risk' adults. J Am Heart Assoc 2012;1:e001354.

106. Gulati M, Black HR, Shaw LJ, et al. The prognostic value of a nomogram for exercise capacity in women. $N$ Engl $\mathrm{J} M e d$ 2005;353:468-75
107. Mora S, Redberg RF, Cui Y, et al. Ability of exercise testing to predict cardiovascular and all-cause death in asymptomatic women: a 20-year follow-up of the lipid research clinics prevalence study. JAMA 2003;290:1600-7.

108. Adamsen L, Midtgaard J, Andersen C, et al. Transforming the nature of fatigue through exercise: qualitative findings from a multidimensional exercise programme in cancer patients undergoing chemotherapy. Eur J Cancer Care (Engl) 2004:13:362-70.

109. Midtgaard J, Stage M, Moller T, et al. Exercise may reduce depression but not anxiety in self-referred cancer patients undergoing chemotherapy. Post-hoc analysis of data from the 'Body \& Cancer' trial. Acta Oncol 2011;50:660-9.

110. Jones LW, Courneya KS, Mackey JR, et al. Cardiopulmonary function and age-related decline across the breast cancer survivorship continuum. J Clin Oncol 2012;30:2530-7.

111. Berger AM, Grem JL, Visovsky C, et al. Fatigue and other variables during adjuvant chemotherapy for colon and rectal cancer. Oncol Nurs Forum 2010;37:E359-69.

112. Brem S, Kumar NB. Management of treatment-related symptoms in patients with breast cancer. Clin J Oncol Nurs 2011;15:63-71.

113. Glen $\mathrm{H}$, Cassidy J. Redefining adjuvant chemotherapy in patients with stage III colon cancer: X-ACT trial. Expert Rev Anticancer Ther 2008;8:547-51.

114. Hutchinson AD, Hosking JR, Kichenadasse $\mathrm{G}$, et al. Objective and subjective cognitive impairment following chemotherapy for cancer: a systematic review. Cancer Treat Rev 2012;38:926-34.

115. Carayol M, Bernard P, Boiche J, et al. Psychological effect of exercise in women with breast cancer receiving adjuvant therapy: what is the optimal dose needed? Ann Oncol 2013;24:291-300.

116. Demark-Wahnefried W, Case LD, Blackwell K, et al. Results of a diet/exercise feasibility trial to prevent adverse body composition change in breast cancer patients on adjuvant chemotherapy. Clin Breast Cancer 2008;8:70-9.

117. Courneya KS, Segal RJ, Mackey JR, et al. Effects of aerobic and resistance exercise in breast cancer patients receiving adjuvant chemotherapy: a multicenter randomized controlled trial. J Clin Oncol 2007;25:4396-404.

118. Mock V, Frangakis C, Davidson NE, et al. Exercise manages fatigue during breast cancer treatment: a randomized controlled trial. Psychooncology 2005;14:464-77.

119. Schwartz AL, Winters-Stone K, Gallucci B. Exercise effects on bone mineral density in women with breast cancer receiving adjuvant chemotherapy. Oncol Nurs Forum 2007;34:627-33.

120. Segal R, Evans W, Johnson D, et al. Structured exercise improves physical functioning in women with stages I and II breast cancer: results of a randomized controlled trial. J Clin Oncol 2001;19:657-65.

121. Gjerset GM, Fossa SD, Courneya KS, et al. Exercise behavior in cancer survivors and associated factors. J Cancer Surviv 2011;5:35-43.

122. Vallance JK, Courneya KS, Plotnikoff RC, et al. Analyzing theoretical mechanisms of physical activity behavior change in breast cancer survivors: results from the activity promotion (ACTION) trial. Ann Behav Med 2008;35:150-8.

123. Midtgaard J. Theoretical and practical outline of the Copenhagen PACT narrative-based exercise counselling manual to promote physical activity in post-therapy cancer survivors. Acta Oncol 2013;52:303-9.

124. Underwood JM, Townsend JS, Stewart SL, et al Surveillance of demographic characteristics and health behaviors among adult cancer survivors-Behavioral Risk Factor Surveillance System, United States, 2009. MMWR Surveill Summ 2012:61:1-23. 